\title{
Radiation Stability of the BSA Modified Biocompatible Magnetic Fluid
}

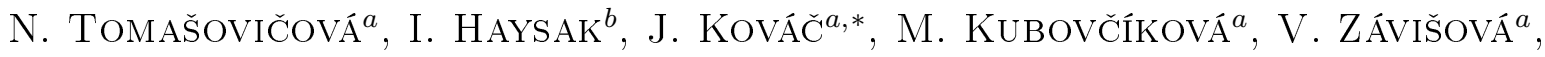

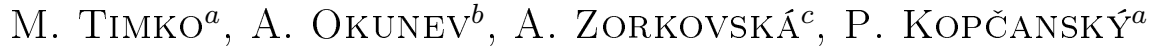 \\ ${ }^{a}$ Institute of Experimental Physics, Slovak Academy of Sciences, Watsonova 47, 04001 Košice, Slovakia \\ ${ }^{b}$ Uzhorod National University 46 Pidhirna St., Uzhorod 88000, Ukraine \\ ${ }^{c}$ Institute of Geotechnics, Slovak Academy of Sciences, Watsonova 45, 04001 Košice, Slovakia
}

\begin{abstract}
The aim of the presented work was to investigate the stability of biocompatible magnetic fluid, i.e. water-based magnetic fluid containing magnetite nanoparticles stabilized by surfactant sodium oleate and modified by bovine serum albumin (BSA) after electron irradiation. Samples with the same concentration of $\mathrm{Fe}_{3} \mathrm{O}_{4}$ but different mass ratio $\mathrm{BSA} / \mathrm{Fe}_{3} \mathrm{O}_{4}(\mathrm{w} / \mathrm{w}=0.25,1.0$ and 2.5) were studied. The electron irradiation caused about $10 \%$ reduction of the saturation magnetization in the samples with $\mathrm{w} / \mathrm{w} \mathrm{BSA} / \mathrm{Fe}_{3} \mathrm{O}_{4}$ ratio of 0.25 and less than $5 \%$ in the samples with $\mathrm{w} / \mathrm{w} \mathrm{BSA} / \mathrm{Fe}_{3} \mathrm{O}_{4}$ ratio of 1 and 2.5.
\end{abstract}

DOI: 10.12693/APhysPolA.126.262

PACS: $75.50 . \mathrm{Mm}, 61.30 . \mathrm{Gd}, 64.70 . \mathrm{Md}$

\section{Introduction}

Magnetic fluids are widely used for medical applications. In order to choose magnetic fluids for a specific application, a comprehensive characterization is needed. Coating can improve oxidation resistance, mechanical stability, and biocompatibility. The preferential killing of cancer cells without damaging normal cells has been a desired goal in cancer therapy for many years. Magnetic fluids hyperthermia is one of the promising approaches in cancer therapy. In work [1] it was shown that the combined thermotherapy and radiation with 20 Gy was as effective as the radiation at three times higher dose. From this point of view it is important to study the influence of the irradiation on physical properties and colloidal stability of magnetic fluids for bioapplications. In our previous works $[2,3]$ we have investigated the radiation stability of water-based magnetic fluids with magnetic particles coated with natrium oleate and the same magnetic fluid modified with polyethylene glycol (PEG) of various molar weight and molar ratio of $\mathrm{Fe}_{3} \mathrm{O}_{4}$ and PEG. In this work we investigate the stability of water-based magnetic fluid containing magnetite nanoparticles stabilized by sodium oleate and modified by bovine serum albumin (BSA) after electron irradiation.

\section{Experiment}

The details of the preparation of magnetic fluid with defined $\mathrm{w} / \mathrm{w} \mathrm{BSA} / \mathrm{Fe}_{3} \mathrm{O}_{4}$ ratios, as well as characterization of prepared samples were described by Siposova et al. [4].

The irradiation of samples was conducted by electrons of Strontium-Yttrium beta source setup. The

\footnotetext{
*corresponding author; e-mail: jkovac@saske.sk
}

beta setup consists of 16 Strontium sources packed in a disk cassette of $35 \mathrm{~cm}$ diameter. The source radiates continuous electron spectrum $0-2.27 \mathrm{MeV}$ with average energy $0.6 \mathrm{MeV}$ and density of the electrons $\Phi=0.98 \times 10^{7}$ electrons $/\left(\mathrm{cm}^{2} \cdot \mathrm{s}\right)$. The samples in a polyethylene container were exposed at the distance of $20 \mathrm{~cm}$ in front of the source. The magnetization curves, infrared spectra, X-ray measurements and zeta potential were measured by SQUID magnetometer (Quantum Design MPMS 5XL), FTIR spectrometer FTLA2000 instrument (ABB, resolution $4 \mathrm{~cm}^{-1}$ ) by Attenuated Total Reflectance measurements with diamond window, X-ray Bruker D8 Advance diffractometer, working with the $\mathrm{Cu}$ $\mathrm{K}_{\alpha}$ radiation and by the dynamic light scattering measurements using a Zetasizer Nano ZS by Malvern Instruments, respectively.

\section{Results and discussion}

BSA has a good biocompatibility and no cytotoxicity, and is similar to human serum albumin (HSA) [5]. The properties of BSA-modified magnetic fluids (MF BSA) were determined by different methods [4] and it was shown, that they are colloidal stable for the $\mathrm{w} / \mathrm{w}$ $\mathrm{BSA} / \mathrm{Fe}_{3} \mathrm{O}_{4}$ ratios up to 1.1. Therefore for the study of the radiation stability of MF $\mathrm{BSA}$, two colloidal stable samples with the w/w BSA $/ \mathrm{Fe}_{3} \mathrm{O}_{4}$ ratio of 0.25 and 1 and one sample with moderate stability with the $\mathrm{w} / \mathrm{w}$ $\mathrm{BSA} / \mathrm{Fe}_{3} \mathrm{O}_{4}$ ratio of 2.5 were chosen. The prepared samples were irradiated with different doses $1 \mathrm{~Gy}, 2 \mathrm{~Gy}, 4 \mathrm{~Gy}$, 8 Gy, 16 Gy, 32 Gy, 100 Gy, 256 Gy, 512 Gy and 1024 Gy, respectively.

Figure 1 shows the dependences of relative saturated magnetization of the samples on the applied dose. The results show about $10 \%$ reduction of the saturated magnetization due to irradiation for the sample with the $\mathrm{w} / \mathrm{w}$ $\mathrm{BSA} / \mathrm{Fe}_{3} \mathrm{O}_{4}$ ratio of 0.25 , while in the case the sample with the w/w BSA $/ \mathrm{Fe}_{3} \mathrm{O}_{4}$ ratio of 1 and 2.5 only a slight 
reduction of saturated magnetization (less than 5\%) is observed. The results suggest that with increasing $\mathrm{w} / \mathrm{w}$ $\mathrm{BSA} / \mathrm{Fe}_{3} \mathrm{O}_{4}$ ratio the samples are more stable against the irradiation. However, the results obtained from measurements of hydrodynamic diameter are in the contradiction.

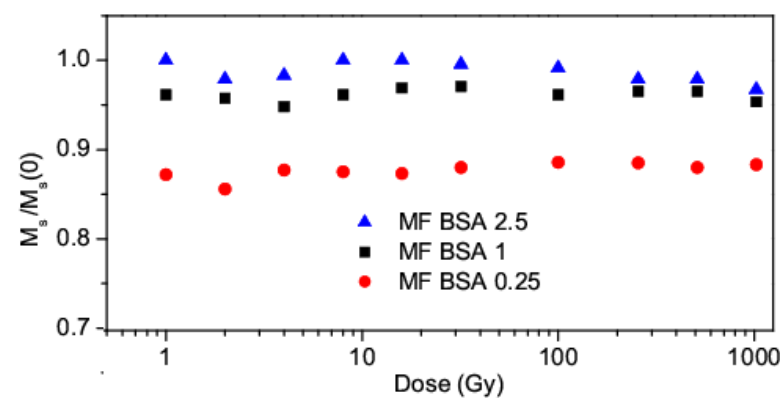

Fig. 1. Dependence of $M_{s} / M_{s}(0)$ on irradiation doses of MF BSA.

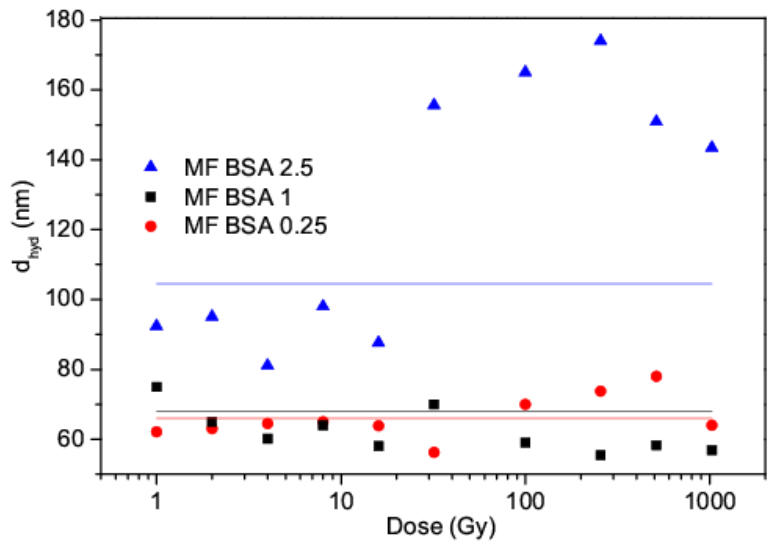

Fig. 2. Hydrodynamic diameter of the modified magnetic particles as a function of dose. The lines represent hydrodynamic diameter before irradiation.

Figure 2 shows that the highest changes in hydrodynamic diameter after irradiation are observed in the sample with the $\mathrm{w} / \mathrm{w} \mathrm{BSA} / \mathrm{Fe}_{3} \mathrm{O}_{4}$ ratio 2.5. These results suggest that the increase of hydrodynamic diameter is caused mainly by degradation of BSA. With the aim to confirm this suggestion, the infrared spectra of all samples after irradiation were measured. For the samples with $\mathrm{w} / \mathrm{w} \mathrm{BSA} / \mathrm{Fe}_{3} \mathrm{O}_{4}$ ratio of 0.25 and 1 no changes in infrared spectra are observed, but in the case of the sample with w/w BSA $/ \mathrm{Fe}_{3} \mathrm{O}_{4}$ ratio of 2.5, the significant change is observed in the region $2840 \mathrm{~cm}^{-1}-3000 \mathrm{~cm}^{-1}$, which corresponds to $\mathrm{C}-\mathrm{H}$ vibrations in sodium oleate and BSA, as well as at $1244 \mathrm{~cm}^{-1}$, which corresponds to $(\mathrm{C}-\mathrm{N})+(\mathrm{N}-\mathrm{H})$ vibration in BSA (Fig. 3). The X-ray diffraction data confirmed that magnetic particles were not affected by irradiation.

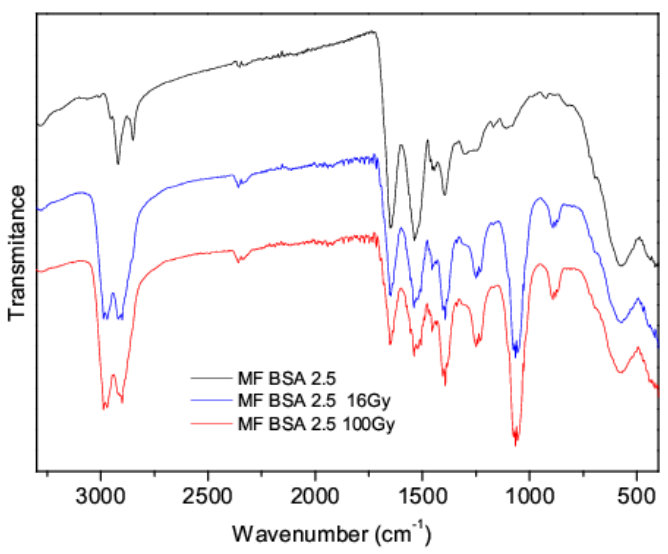

Fig. 3. Infrared spectra of MF BSA with w/w $\mathrm{BSA} / \mathrm{Fe}_{3} \mathrm{O}_{4}$ ratio 2.5 before and after irradiation (spectra are shifted vertically for clarity).

\section{Conclusions}

The obtained results suggest that irradiation with small doses causes release of BSA and this process leads to the reduction of hydrodynamic diameter. The irradiation with doses higher than 16 Gy causes conformational and structural changes in released BSA and consequently to the creation of BSA aggregates in sample with high concentration of BSA.

\section{Acknowledgments}

This work was supported by the Slovak Academy of Sciences grants VEGA 2/0045/13 and 1/0861/12, Slovak Ministry of Education of Slovakia - Agency for Structural Funds of EU in frame of project No. 26110230061, 6220120021 and 6220120033, and by Ministry of Education and Science of Ukraine in the framework of project No. 0109U000873.

\section{References}

[1] M. Johannsen, B. Thiesen, U. Gneveckow, K. Taymoorian, N. Waldofner, R. Scholz, S. Deger, K. Jung, S.A. Loening, A. Jordan, Prostate 66, 97 (2006).

[2] N. Tomasovicova, I. Haysak, M. Koneracka, J. Kovac, M. Timko, V. Zavisova, A. Okunev, A. Parlag, A. Fradkin, P. Kopcansky, arXiv/1004.3448v2.

[3] N. Tomasovicova, I. Haysak, M. Koneracka, J. Kovac, M. Timko, V. Zavisova, A. Okunev, A. Parlag, A. Fradkin, V. Sakhno, P. Kopcansky, Acta Physica Polonica A 121, 1302 (2012).

[4] K. Siposova, M. Kubovcikova, Z. Bednarikova, M. Koneracka, V. Zavisova, A. Antosova, P. Kopcansky, Z. Daxnerova, Z. Gazova, Nanotechnology 23, 055101 (2012).

[5] Y.Z. Zhang, B. Zhou, Y.X. Liu, C.X. Zhou, X.L. Ding, Y. Liu, J. Fluoresc. 18, 109 (2008). 